\title{
Fernando Tola Mendoza (1915-2017). In memoriam
}

Un peruano universal, en palabras de Edgardo Rivera Martínez, Fernando Tola Mendoza realizó una obra única en las letras peruanas, y su partida deja un lugar irremplazable no solo en el medio intelectual peruano y argentino, donde su labor dejó recordada huella, sino también en la Academia Peruana de la Lengua, de la que fue miembro correspondiente desde 1995. En recuerdo de su esposa, la académica argentina Carmen Dragonetti, a Fernando Tola no le gustaba «aparecer», poseía una modestia propia de los grandes espíritus. El nombre de Tola es conocido y celebrado en las aulas universitarias a través de sus libros; más que promesas quedó una extensa obra que comprende una vida de rigor, investigaciones y traducciones, y por su legado es uno de los intelectuales peruanos más importantes del siglo XX.

Fernando Tola Mendoza nació en Lima en octubre de 1915. Cursó la educación secundaria en Bruselas, en la sección griega del Athénée Saint-Gilles. De regreso a Perú estudió Humanidades y Derecho en la Universidad Nacional Mayor de San Marcos. Obtuvo su grado de doctor en Literatura en 1939. Tola dominaba más de catorce idiomas; entre ellos el latín, griego, sánscrito, pali, chino, tibetano y japonés. Se dedicó desde temprano a la docencia universitaria en su alma mater, en la que fue profesor titular de griego, latín, sánscrito, budismo e hinduismo entre 1935 y 1963; y profesor emérito desde 1972, en uno de los primeros centros de 
formación de lingüistas y traductores del Perú, el Instituto de Lingüística y Filología. Tola realizó su vida académica en Perú hasta 1970, y se desempeñó además como director del Instituto de Filología, director y fundador del Instituto de Lenguas y Culturas Orientales y director de la revista Sphinx. Desde entonces se instaló en Argentina, donde se desempeñó como catedrático y vivió junto con su esposa Carmen Dragonetti y sus dos hijas, Eleonora y Florencia, quienes se dedican a la investigación.

El legado intelectual de Fernando Tola Mendoza se destaca por dos actividades fundamentales, la investigación y la traducción. Su labor académica como director del Instituto de Lingüística y Filología en la Universidad Nacional Mayor de San Marcos dejó valiosas publicaciones así como gestó las últimas generaciones de latinistas y orientalistas peruanos, entre los que se encuentran, entre otros, José León Herrera, Dora Bazán Montenegro y el escritor Edgardo Rivera Martínez. En San Marcos, Tola fundó la revista Sphinx (1936), de la que fue director hasta 1963, donde se publicaron traducciones del quechua, del latín y del sánscrito. Sphinx es la única publicación en el Perú dedicada al estudio riguroso y a la traducción de las culturas clásicas orientales y occidentales. En ella, Tola publicó sus primeras traducciones: Meghadūta. La nube mensajera, del poeta hindú Kālidāsa, en 1937; luego traducciones de Demetrio Mosco; y, en 1938, la Antología del Niti y Vairagya y S'ringara S'atakam, de Bhartrihari, dos de los textos más influyentes de poesía en sánscrito. Con estas versiones comenzó su incansable labor como traductor de la más encumbrada poesía en sánscrito. Entre 1939 y 
1940 publicó los dos primeros cantos de la Bhagavad Gìtā, que luego aparecería, ampliada, en 1977. Posteriormente, lanzó una serie bilingüe dedicada a la publicación de versiones castellanas de clásicos occidentales y orientales. En ella aparecieron sus estudios sobre las lenguas y culturas clásicas, así como traducciones; en 1956 la Mundaka Upanishad, con un aparato crítico de notas, que caracterizaría a sus versiones eruditas posteriores, la primera selección de los Himnos del Rig Veda (1961), que amplió más adelante. Entre 1955 y 1964, Tola recibió una serie de becas que le permitieron realizar viajes académicos a Europa. Estudió en Grecia, Francia, Alemania y Holanda. Estas estadías le permitieron concretar diversas publicaciones que definieron su perfil académico. En 1964 la Unesco le concedió una beca que le permitió estudiar en la India por seis años. En la India se desempeñó como agregado cultural en la Embajada de Perú. Fruto de sus años de estudios, en 1968, publicó en Buenos Aires la traducción de los Himnos del Atharva Veda y una selección de los célebres Himnos del Rig Veda. A partir de esta estancia, Tola se dedicó casi exclusivamente a la difusión de la cultura y filosofía de la India y, junto con Carmen Dragonetti, se convirtió en uno de los mayores investigadores de las filosofías orientales.

Hacia 1970 Tola se instaló en Argentina, donde fue profesor de sánscrito y filosofía de la India en la Universidad de Buenos Aires e investigador superior en el Consejo Nacional de Investigaciones Científicas y Técnicas. En trabajo conjunto con Dragonetti, Fernando Tola publicó investigaciones sobre filosofía oriental en lengua española, celebradas por la academia 
internacional. Su Filosofía y literatura de la India, aparecida por primera vez en 1983, ha conocido numerosas ediciones. Su estudio sobre el nihilismo budista, Nihilismo budista. La doctrina de la vaciedad, ha sido traducido al inglés y al portugués, y ha sido publicado en ediciones brasileñas, mexicanas e hindúes. Las publicaciones y traducciones de Tola y Dragonetti se enmarcan en un gran proyecto de investigación en que se cuestionan los mitos sobre la filosofía oriental, que postulan la racionalidad de la filosofía europea, e invitan a evitar la división entre tradiciones orientales y occidentales. En vez de ello, Tola y Dragonetti proponen hablar de un pensamiento humano universal. Su estudio de la filosofía yoga, La filosofía yoga. Un camino místico universal, publicado en el 2005, por ejemplo, se enmarca dentro de este proyecto. Ubican el sistema filosófico yoga dentro del sistema $S \bar{a}$ khya, planteando que la irracionalidad, como el trance en el yoga, señala una faceta de la experiencia humana. Una de sus contribuciones más importantes, de vasto carácter, que se encuentra en el marco de esta perspectiva académica, es la publicación de On the Myth of the Opposition between Indian Thought and Western Philosophy, en el 2004, que ha aparecido en español en una edición ampliada, en el 2008, con el título Filosofía de la India (del Veda al Vedanta, el sistema Sāmkhya). En sintonía con La filosofía yoga, este trabajo plantea una crítica a la visión hegeliana de la denominación «filosofía», y discute la dicotomía entre racionalidad/irracionalidad que se atribuye a la filosofía occidental y oriental respectivamente. Se plantea la necesidad de encontrar similitudes entre los sistemas filosóficos europeos y orientales, encontrando y 
analizando temas y metodologías en la filosofía similares hasta el siglo XVII. Tola y Dragonetti plantean que en la India sí ha existido una filosofía, cuyos asuntos poseen cierta afinidad con la filosofía europea, como la división espíritu y materia, que se puede denominar así «Filosofía de la India». Este trabajo ha sido comentado y celebrado por indianistas, y resulta uno de los aportes contemporáneos definitivos de la obra de Tola y Dragonetti al quehacer intelectual de la filosofía oriental.

Dentro del conjunto de la obra de Fernando Tola, las traducciones han sido una actividad que resultó un modo de desentrañar las culturas y filosofías orientales. Así, Tola ha acompañado la reflexión filosófica con traducciones en toda su vida académica, de allí que sea difícil comentar ambas actividades por separado. Desde los inicios de su carrera intelectual, Fernando Tola ha insertado el español en la discusión filosófica y lo ha convertido en una herramienta de debate, así como un medio de producción y difusión de conocimiento. Este es uno de sus legados más importantes en el campo intelectual latinoamericano. En conjunto con Carmen Dragonetti, ha publicado versiones de textos inéditos de la tradición oriental en castellano, los cuales también han sido fuentes de traducciones a otros idiomas. A partir de su actividad de hermeneuta, el trabajo de Fernando Tola modela los estudios académicos latinoamericanos en el estudio riguroso de la filosofía oriental a partir de los textos fuentes originales, sin dependencia de versiones del alemán, inglés o francés, y también nutre el archivo de la academia y literatura en español con la traducción de obras maestras de las literaturas orientales. En este aspecto es, además, uno de los grandes 
traductores latinoamericanos: su obra ha enriquecido la experiencia de la lengua española, acomodándola a asuntos disímiles a su tradición, así como a otros regímenes. Al verter textos canónicos orientales, Tola introduce la lengua española a otros usos, ampliándola y enriqueciendo su registro y experiencia.

En 1971 Tola publicó la primera traducción del poema pastoral Gìta Govinda, obra maestra del poeta indio Jayadeva. Ese mismo año, apareció su traducción de Cien poemas de amor, de Amaru, principal autor de la lírica erótica en sánscrito; y posteriormente, en 1973, una selección de Los consejos de la Celestina (Kuttanìmatam), de Dāmodara Gupta, compuesta por más de mil estanzas, a las que acompañan las versiones de los poemas de Gangadevi y Mayura. En el 2001, apareció una versión ampliada de la Antigua poesía budista. La serpiente y otros poemas del Sutta Nipāta, colección de suttas en pāri, en prosa y verso. Estas versiones confirman el gran aporte de Tola en la difusión de la lírica en sánscrito, que acompañó y complementó su estudio de las filosofías orientales. A partir de la década de los setenta, siempre conjuntamente con Carmen Dragonetti, emprendió la traducción de textos canónicos de los diversos sistemas filosóficos de la India. Aparecieron en su totalidad, en 1973, Los Yogasutras de Patañjali, aforismos cuya traducción está acompañada de comentarios explicativos. Ese mismo año, Tola y Dragonetti publicaron seis upanishads en Doctrinas secretas de la India: Upanishads. En 1980, apareció Budismo Mahāyāna, que agrupa la traducción de documentos en tibetano, sánscrito y chino.

En 1990 se creó en México la Asociación Latinoamericana de Estudios Budistas, impulsada por el 
Centro de Estudios Orientales del Colegio de México. La Asociación lanzó en 1991 la Revista de Estudios Budistas y designó como directores a Fernando Tola y Carmen Dragonetti. A lo largo de los trece números de la Revista, Tola y Dragonetti publicaron no solo amplios estudios, sino también primeras versiones en castellano de textos esenciales del saber oriental, tibetano, chino, pāli y sánscrito. Entre los años 1999 y 2002 aparecieron sus traducciones de sutras esenciales: El Sutra del Loto de la verdadera Doctrina. Saddharmapuñ̄kasūtra, Wu Liang I Ching. El Sutra de los infinitos significados, traducido del chino, y Los cinco Sutras del Mahāyāna. Posteriormente, Tola y Dragonetti publicaron traducciones del pāli, como la importante Udana. Palabra de Buda, conjunto de relatos sobre la vida de Buda y principio de la doctrina budista. En el último tramo de su actividad intelectual, Tola prosiguió su infatigable trabajo como indianista; en el 2010 publicó Digha Nikaya. Diálogos mayores de Buda, traducción del pāli de tres suttas, así como revisó y amplió continuamente traducciones anteriores. En su centenario, en el 2015, recibió varios homenajes en Argentina, donde siguió incansable en su labor intelectual. El año siguiente apareció una revisión crítica de la indología europea, Ideología o filosofía: el nazismo, Heidegger y Frauwallner, en el que se estudian las similitudes del caso del filósofo alemán Martin Heidegger y el indólogo austríaco Erich Frauwallner en los vínculos de sus obras con el nazismo. En esta publicación, Tola y Dragonetti realizan una visión crítica de la indología alemana, en sintonía con la lectura crítica de Hegel realizada en Filosofía de la India. Solo su partida, ocurrida en julio de 2017, interrumpió sus traducciones 
y contribuciones académicas. Para esta fecunda labor, Tola no habría quizá poseído el mismo aliento sin la compañía de su compañera de vida, la doctora Carmen Dragonetti, en quien Tola encontró a su par intelectual. La obra de Tola así como su obra conjunta con Dragonetti es ejemplo de ideal humanista.

En Perú, Fernando Tola recibió la Orden del Sol en el grado de Gran Oficial en 1984, y su legado está aún por ser difundido y reconocido. En un país que no suele reconocer la excelencia, el reconocimiento de la obra de Fernando Tola es una deuda que se debe honrar mediante la difusión de sus contribuciones a la academia peruana. Gracias a su magisterio se formaron generaciones de filólogos en la Universidad Nacional Mayor de San Marcos, quienes luego fundaron las primeras escuelas de lingüística y de traducción en el Perú. Por su brillo intelectual y humildad, su recuerdo sigue vivo en sus discípulos, y en los alumnos de sus discípulos, quienes escuchamos anécdotas de Fernando Tola y su don de lenguas: sabio y traductor que era medida de la devoción al conocimiento. Vive Tola en su obra que se comenta y estudia en las facultades de humanidades, y que forma vocaciones, en los lectores de poesía que con asombro leen sus traducciones, en un amplio legado que ha modelado orientalistas, de cuya gratitud son muestra los diversos homenajes que ha recibido por su centenario y su partida. Por ello Fernando Tola habita entre nosotros: ha partido a otro viaje el maestro, pero sus palabras persistirán en las generaciones de lectores de hoy y los que están por llegar. 